\title{
PENGARUH TRUNK CONTROL ACTIVITY TERHADAP TINGKAT KEMANDIRIAN AKTIVITAS KEHIDUPAN SEHARI-HARI (ACTIVITY OF DAILY LIVING) PASIEN PASCA STROKE
}

\author{
Mudatsir Syatibi, Hendri Kurniawan, Rita Untari \\ Kementerian Kesehatan, Politeknik Kesehatan Surakarta, Jurusan Okupasi Terapi
}

\begin{abstract}
Trunk Control, Activity Of Daily Living. The purpose of this study was to determine the effect of trunk control activity on the level of post-stroke patients independence in performing activities of daily life (activity of daily living). The study design was performed according to quasi experimental design with a control group pretest-posttest design. The study population was patients with post-stroke conditions that obtain in Clinical intervention Sasana Husada Group. Sampling using quota sampling with a sample size of 30 people. Data analysis using independent t-test using SPSS version 11.5. Results of analysis using independent $t$-test showed the value of $F=$ 0.611 (equal variances assumed), $t=3.654$ and $p$-value $=0.001$. Trunk control activity significantly affect the level of independence of daily life activity (activity of daily living) post-stroke patients.
\end{abstract}

Keywords: Trunk Control, Activity Of Daily Living

Abstrak: Trunk Control, Activity Of Daily Living. Tujuan penelitian ini adalah untuk mengetahui pengaruh trunk control activity terhadap tingkat kemandirian penderita pasca stroke dalam melakukan aktivitas kehidupan sehari-hari (activity daily of living). Desain penelitian dilakukan menurut rancangan quasi experiment dengan control group pretest-post test design. Populasi penelitian adalah pasien dengan kondisi pasca stroke yang memperoleh intervensi di Klinik Sasana Husada Grup. Pengambilan sampel menggunakan teknik quota sampling dengan jumlah sampel sebanyak 30 orang. Analisis data menggunakan independent t-test dengan memakai program SPSS versi 11.5. Hasil analisis menggunakan independent $t$-test menunjukkan nilai $\mathrm{F}=0,611$ (equal variances assumed), nilai $\mathrm{t}=3,654$ dan $\mathrm{p}$-value $=0,001$. Trunk control activity berpengaruh secara signifikan terhadap tingkat kemandirian aktivitas kehidupan seharihari (activity daily of living) pasien pasca stroke.

Kata kunci : Trunk Control, Activity Of Daily Living

\section{PENDAHULUAN}

Stroke, sebagai salah satu penyebab morbiditas dan mortalitas, menunjukkan angka kecenderungan yang semakin meningkat dari tahun ke tahun. Menurut Lloyd-Jones et al. (2010), stroke menjadi penyebab kematian terbanyak dan disabilitas yang lama di seluruh dunia.
Angka kejadian stroke di Indonesia meningkat tajam menjadi urutan ketiga penyebab kematian setelah penyakit jantung dan kanker. Angka kejadian stroke di Indonesia tertinggi dibandingkan negara-negara lain yang memiliki resiko sama dengan di Indonesia (Gemari, 2008). 
Stroke adalah cedera vascular akut pada otak yang bersifat mendadak atau tiba-tiba. Cedera dapat disebabkan oleh sumbatan pembuluh darah, penyempitan pembuluh darah atau pecahnya pembuluh darah. Semua ini menyebabkan kurangnya pasokan darah yang memadai ke otak. Stroke mungkin menampakkan gejala, mungkin tidak (silent stroke), tergantung tempat dan ukuran kerusakan.

Hasil studi ASNA (ASEAN Neurological Association) dari 28 rumah sakit yang ada di Indonesia menemukan bahwa kejadian stroke sering terjadi pada rentang usia $45-65$ tahun $(53,1 \%)$ dengan perbandingan pria lebih banyak dibandingkan wanita. Studi ini juga menemukan adanya pergeseran usia penderita stroke dari yang semula menyerang orang usia lanjut ke usia produktif, dimana $12,9 \%$ kejadian stroke menyerang usia di bawah 45 tahun. Gangguan motorik menjadi gejala yang paling banyak dikeluhkan oleh penderita pasca stroke (Misbach \& Ali, 2002).

Gangguan postural control merupakan permasalahan lanjutan yang dialami oleh pasien pasca stroke. Kontrol postural dibutuhkan dalam seluruh aspek gerakan fungsional (Raine et al., 2009) terkait dengan perannya sebagai dasar untuk keseimbangan postur sehingga gerak menjadi terkontrol dan efisien. Sebagaimana diketahui bahwa kemampuan untuk mempertahankan keseimbangan dalam berbagai aktivitas dan kondisi merupakan salah satu faktor penting dalam kontrol motorik yang diperlukan dalam kehidupan sehari-hari. Oleh karena itu latihan yang bertujuan untuk melatih keseimbangan (training balance movement) menjadi hal yang paling krusial dalam program rehabilitasi.
Trunk control merupakan komponen yang terintegrasi dalam postural control. Gangguan trunk control, sebagai salah satu permasalahan motorik yang dihadapi oleh penderita pasca stroke, mengakibatkan penderita pasca stroke kesulitan untuk melakukan aktivitas secara efektif dan efisien. Hal ini mengingat trunk mempunyai peran dalam menyediakan atau memberikan dasar stabilitas untuk melakukan mobilitas tubuh. Trunk juga menjadi dasar pada aktivitas pernapasan, bicara, keseimbangan, fungsi ekstremitas superior dan inferior, kemampuan untuk melakukan aktivitas kehidupan sehari-hari dan ambulasi (Verheyden, 2007). Namun program rehabilitasi pada pasien pasca stroke pada umumnya lebih fokus pada gangguan motorik di ekstremitas atas maupun bawah.

Pasca serangan stroke, kemampuan untuk mengontrol keseimbangan pada posisi duduk maupun berdiri merupakan kemampuan motorik yang sangat mendasar atau fundamental untuk meraih atau mencapai kemampuan dalam melakukan aktivitas sehari-hari (everyday activities) secara mandiri (Verheydan, 2007). Kemampuan mempertahankan tubuh pada posisi duduk adalah prioritas posisi yang harus dilatihkan dan dicapai oleh penderita pasca stroke, untuk selanjutnya dilatihkan pada posisi berdiri dan kemampuan berjalan. Restorasi posisi duduk akan memberikan stimulasi inervasi secara bilateral pada trunk dan otot-otot lingkar bahu serta panggul. Selain itu, kemampuan penderita pasca stroke mengoNtrol tubuh pada posisi duduk menjadi kunci untuk tercapainya postural control yang baik (Benaim, 1999). 


\begin{abstract}
Berdasarkan penelitian yang dilakukan oleh Verheydan (2007) diketahui bahwa trunk control tidak hanya menjadi permasalahan bagi penderita pasca stroke pada fase akut namun secara umum juga masih menjadi permasalahan pasien pasca stroke pada fase kronis. Temuan ini mengindikasikan akan pentingnya upaya rehabilitasi secara intensif terhadap trunk control mengingat peran trunk control sebagai komponen dalam kontrol postural.
\end{abstract}

\section{METODE PENELITIAN}

Penelitian dilakukan dengan
rancangan quasi experiment dengan
control group pretest-post test design. Kelompok eksperimen diberikan latihan kontrol trunk (trunk control activity) sedangkan kelompok kontrol menjalani latihan okupasi terapi berupa neurorehabilitation approach, selama lebih kurang 8 minggu. Sampel penelitian adalah pasien dengan kondisi pasca stroke yang memperoleh intervensi di Klinik Sasana Husada Jakarta. Pengambilan sampel (subjek penelitian) menggunakan teknik quota sampling, dengan kriteria sampel adalah pasien pasca stroke dengan onset $<2$ tahun, berusia 30-65 tahun, serangan stroke I dan tidak mengalami gangguan kognitif dan mental.

Variabel penelitian berupa kemampuan trunk control dan tingkat kemandirian aktivitas kehidupan seharihari, merupakan data primer yang diukur menggunakan instrumen Trunk Impairment Scale (TIS) dan instrumen Barthel Index oleh terapis. Data penelitian dianalisis menggunakan uji komparasi $t$ test dengan program SPSS versi 16 for windows.

\section{HASIL PENELITIAN \\ Tabel 1}

Distribusi frekuensi sampel penelitian berdasarkan usia

\begin{tabular}{|c|c|c|}
\hline Usia & Jumlah & $\%$ \\
\hline$<40$ tahun & 3 & 10 \\
\hline $41-60$ tahun & 12 & 40 \\
\hline$>60$ tahun & 15 & 50 \\
\hline Total & 30 & 100 \\
\hline
\end{tabular}

Berdasarkan tabel di atas diketahui proporsi sampel penelitian didominasi oleh sampel berusia $>60$ tahun $(50 \%)$.

Tabel 2

Distribusi skor Trunk Impairment Scale

\begin{tabular}{|c|c|c|c|c|c|c|}
\hline Kelompok & \multicolumn{6}{|c|}{ Skor Trunk Impairment Scale } \\
\hline \multirow[t]{2}{*}{ Penelitian } & \multicolumn{2}{|c|}{ Static Sitting } & \multicolumn{2}{|c|}{$\begin{array}{c}\text { Dynamic } \\
\text { Sitting }\end{array}$} & \multicolumn{2}{|c|}{$\begin{array}{c}\text { Coordinati } \\
\text { on }\end{array}$} \\
\hline & $\begin{array}{l}<7 \\
(\%)\end{array}$ & $\begin{array}{c}7 \\
(\%)\end{array}$ & $\begin{array}{l}<10 \\
(\%)\end{array}$ & $\begin{array}{c}10 \\
(\%)\end{array}$ & $\begin{array}{l}<6 \\
(\%)\end{array}$ & $\begin{array}{c}6 \\
(\%)\end{array}$ \\
\hline Celor & 1 & 14 & 10 & 5 & 8 & 7 \\
\hline erla & $(6,7)$ & $\begin{array}{c}(93,3 \\
)\end{array}$ & $(66,7)$ & $\begin{array}{c}(33, \\
3)\end{array}$ & $\begin{array}{c}(53, \\
3)\end{array}$ & $\begin{array}{c}(46, \\
7)\end{array}$ \\
\hline $\begin{array}{l}\text { Kelompok } \\
\text { Kontrol }\end{array}$ & $\begin{array}{c}3 \\
(20)\end{array}$ & $\begin{array}{c}12 \\
(80)\end{array}$ & $\begin{array}{c}10 \\
(66,7)\end{array}$ & $\begin{array}{c}5 \\
(33,\end{array}$ & $\begin{array}{c}9 \\
(60)\end{array}$ & $\begin{array}{c}6 \\
(40)\end{array}$ \\
\hline
\end{tabular}

Informasi pada tabel 2.

mengindikasikan bahwa sebagian besar (66,7\%) sampel mengalami permasalahan pada kemampuan trunk control, baik pada kelompok perlakuan maupun kelompok kontrol. Permasalahan pada komponen kemampuan trunk control yang paling banyak dialami oleh sampel penelitian adalah pada komponen dynamic sitting $(66,7 \%)$ dan coordination $(56,7 \%)$.

\section{Tabel 3}

Distribusi sampel berdasarkan tingkat kemandirian aktivitas sehari-hari

\begin{tabular}{lcc}
\hline \multicolumn{1}{c}{ Tingkat Kemandirian } & Jumlah & $\%$ \\
\hline Ketergantungan penuh & 1 & 3,3 \\
Ketergantungan berat & 4 & 13,3 \\
Ketergantungan ringan & 18 & 60 \\
Mandiri & 7 & 23,3 \\
\hline \multicolumn{1}{c}{ Total } & 30 & 100 \\
\hline
\end{tabular}


Hasil pemeriksaan awal menggunakan instrumen Barthel Index (tabel 3) dapat diketahui mayoritas sampel penelitian mengalami ketergantungan dalam melakukan aktivitas kehidupan sehari-hari, yaitu sebanyak 76,7\%.

\section{Tabel 4}

Distribusi tingkat kemandirian sampel berdasarkan kemampuan trunk control

\begin{tabular}{|c|c|c|c|c|c|}
\hline \multirow{2}{*}{$\begin{array}{c}\text { Trunk } \\
\text { Impair } \\
\text { ment } \\
\text { Scale }\end{array}$} & \multicolumn{4}{|c|}{ Skor Barthel Index } & \multirow{2}{*}{$\begin{array}{c}\text { Total } \\
(\%)\end{array}$} \\
\hline & $\begin{array}{c}\text { K. } \\
\text { Penuh } \\
0-20 \\
(\%)\end{array}$ & $\begin{array}{c}\text { K. } \\
\text { Berat } \\
21-40 \\
(\%)\end{array}$ & $\begin{array}{c}\text { K. } \\
\text { Ringan } \\
41-60 \\
(\%)\end{array}$ & $\begin{array}{c}\text { Mandiri } \\
61-100 \\
(\%)\end{array}$ & \\
\hline$<23$ & $1(4,2)$ & $\begin{array}{c}4 \\
(16,7)\end{array}$ & $\begin{array}{c}18 \\
(75)\end{array}$ & $1(4,2)$ & $\begin{array}{c}24 \\
(100)\end{array}$ \\
\hline 23 & $0(0)$ & $0(0)$ & $3(50)$ & $3(50)$ & $\begin{array}{c}6 \\
(100)\end{array}$ \\
\hline
\end{tabular}

Tabel 4. menunjukkan bahwa tingkat kemandirian sampel, pada level mandiri, dalam melakukan aktivitas seharihari lebih banyak dicapai oleh sampel yang memiliki kemampuan trunk control yang baik, yaitu sebesar $50 \%$.

\section{Tabel 5.}

Distribusi Perubahan Skor Barthel Index pada Kelompok Perlakuan \& Kontrol

\begin{tabular}{ccccc}
\hline Kel & \multicolumn{3}{c}{ Perubahan Skor Barthel Index } & Total \\
\cline { 2 - 4 } & $0(\%)$ & $\leq 5(\%)$ & $5<(\%)$ & $(\%)$ \\
\hline Perlakuan & 2 & 5 & $8(53,3 \%)$ & 15 \\
& $(13,3 \%)$ & $(33,3 \%)$ & & $(100 \%)$ \\
\hline Kontrol & 14 & 1 & $0(0 \%)$ & 15 \\
& $(93,3 \%)$ & $(6,7 \%)$ & & $(100 \%)$ \\
\hline
\end{tabular}

Tabel 5 menginformasikan bahwa persentase perubahan kemandirian aktivitas kehidupan sehari-hari lebih banyak terjadi pada kelompok perlakuan (pasien yang memperoleh intervensi berupa trunk control activity) yaitu sebesar $86,6 \%$, dibandingkan pasien pada kelompok kontrol yang hanya sebesar $6,7 \%$.

\section{Tabel 6}

Hasil analisis perbedaan trunk control sebelum dan sesudah intervensi pada kelompok perlakuan dan kontrol

\begin{tabular}{ccccc}
\hline Kelompok & $\mathrm{n}$ & $\mathrm{t}$ & $\mathrm{df}$ & Sig. \\
\hline Perlakuan & 15 & $-2,870$ & 14 & 0,012 \\
Kontrol & 15 & 0,594 & 14 & 0,562 \\
\hline
\end{tabular}

Hasil uji paired t-tes pada tabel 6 menunjukkan bahwa trunk control activity memberikan perbedaan yang signifikan pada kemampuan trunk control pasien pasca stroke pada kelompok perlakuan ( $p$ value $=0,012)$ dibandingkan dengan kelompok kontrol ( $p$-value $=0,562)$.

Tabel 7

Hasil analisis perbedaan kemandirian aktivitas kehidupan sehari hari sebelum dan sesudah intervensi pada kelompok perlakuan dan kontrol

\begin{tabular}{ccccc}
\hline Kelompok & $\mathrm{n}$ & $\mathrm{t}$ & $\mathrm{df}$ & Sig. \\
\hline Perlakuan & 15 & $-2,541$ & 14 & 0,024 \\
Kontrol & 15 & $-1,000$ & 14 & 0,334 \\
\hline \multicolumn{4}{r}{ Hasil uji paired t-tes pada tabel 7. }
\end{tabular}

Hasil uji paired t-tes pada tabel 7 . menunjukkan bahwa trunk control activity memberikan perbedaan yang signifikan pada kemandirian aktivitas kehidupan sehari-hari pasien pasca stroke ( $\mathrm{p}$-value = 0,024), sedangkan pada kelompok kontrol tidak berbeda secara signifikan.

\section{Tabel 8}

Hasil analisis perbedaan tingkat kemandirian aktivitas kehidupan seharihari antara kelompok perlakuan dan kontrol

\begin{tabular}{cccc}
\hline $\mathrm{F}$ & $\mathrm{df}$ & $\mathrm{t}$ & Sig. \\
\hline 0,611 & 18 & 3,654 & 0,001 \\
\hline Hasil & analisis & pada & tabel
\end{tabular}
menunjukkan terdapat perbedaan yang bermakna pada kemandirian aktivitas kehidupan sehari-hari antara kelompok yang memperoleh intervensi berupa trunk control activity dengan kelompok yang diintervensi dengan neurorehabilitation approach (kontrol). 


\section{PEMBAHASAN}

Insidensi dan prevalensi stroke paling besar terjadi pada manula (Centers for Disease Control and Prevention (CDC), 2007). Fakta ini dibuktikan dengan data sampel penelitian pada tabel 1. yang menginformasikan bahwa proporsi sampel penelitian didominasi oleh sampel berusia > 60 tahun $(56,7 \%)$. Umur turut mempengaruhi gangguan keseimbangan pasien pasca stroke. Faktor usia berhubungan dengan proses penurunan fungsi sistem sensori afferen (sensory afferent systems) dan sistem neuromuskular (neuromuscular system) (Shumway-Cook \& Woollacott, 2001).

Gangguan keseimbangan pada pasien pasca stroke dapat disebabkan oleh berbagai gangguan pada sistem fisiologis yang mengatur postural control seperti : sensory afferents, strategi gerak (movement strategies), biomechanical constraints, proses kognitif (cognitive processing) dan persepsi tubuh pada posisi tegak (perception of verticality). Identifikasi terhadap faktor yang menyebabkan gangguan keseimbangan harus dilakukan secara kritis dan selanjutnya harus ditindaklanjuti dengan penanganan secara selektif, aktif dan intensif (Barros de Oliveira, et al., 2008).

Trunk mempunyai peran dalam menyediakan atau memberikan dasar stabilitas untuk melakukan mobilitas tubuh. Trunk juga menjadi dasar pada keseimbangan, fungsi ekstremitas superior dan inferior, kemampuan untuk melakukan aktivitas kehidupan sehari-hari dan ambulasi (Verheyden, 2007). Hasil studi tersebut sesuai dengan hasil penelitian ini, yaitu berdasarkan analisis komparatif (tabel 8) menunjukkan bahwa terdapat perbedaan yang bermakna pada kemandirian aktivitas kehidupan sehari- hari antara kelompok yang memperoleh intervensi berupa trunk control activity dengan kelompok yang diintervensi dengan neurorehabilitation approach. Dengan kata lain trunk control activity memberikan pengaruh yang signifikan terhadap peningkatan kemandirian dalam melakukan aktivitas sehari-hari pada pasien pasca stroke. Hasil analisis ini diperjelas pula oleh data deskriptif menunjukkan bahwa perubahan kemandirian aktivitas kehidupan seharihari lebih banyak dicapai oleh pasien yang memperoleh intervensi trunk control activity (tabel 5.).

Trunk control activity mampu memberikan perubahan berupa peningkatan kemampuan trunk control dan perubahan kemampuan trunk control tersebut memberikan kontribusi terhadap peningkatan kemandirian dalam melakukan aktivitas kehidupan sehari-hari pasien pasca stroke (tabel 5). Keadaan ini turut pula dipengaruhi oleh onset, usia dan kedisiplinan mengikuti terapi (kontinuitas terapi) yang disinyalir turut mempengaruhi proses recovery sel saraf pasca stroke. Hal ini sesuai dengan teori yang menyebutkan bahwa terdapat berbagai faktor yang turut mempengaruhi tingkat kemandirian pasien pasca stroke diantaranya : onset stroke, pengulangan serangan stroke, adaptasi diri terhadap kondisi dan kontinuitas terapi (Barros de Oliveira, et al.., 2008). Pada penelitian ini variasi variabel-variabel tersebut tidak dapat dikondisikan secara optimal.

Kontinuitas terapi terkait dengan jumlah input sensorimotor yang diperlukan dalam proses recovery sel saraf sebagai pendukung pemulihan kemampuan fungsional. Input somatosensoris ke cortex motorik berperan penting (kritis) dalam proses 
pembelajaran kembali kemampuan motorik (motor relearning) pada pasien pasca stroke. Peningkatan respon cortex sensorimotor terhadap stimulasi somatosensoris setelah periode pasca stroke subakut dapat berkontribusi terhadap perbaikan kemampuan motorik (motor recovery). Peningkatan aktivitas pada area sensorimotor telah terbukti berkorelasi dengan peningkatan pemulihan pasien pasca stroke (Schaechter et al., 2004).

\section{KESIMPULAN DAN SARAN}

Trunk control activity berpengaruh secara signifikan terhadap tingkat kemandirian aktivitas kehidupan seharihari (activity daily of living) pasien pasca stroke. Latihan trunk control secara bergradasi sebaiknya dilakukan sedini mungkin agar mampu memberikan daya ungkit terhadap kemandirian aktivitas kehidupan sehari-hari.

\section{DAFTAR RUJUKAN}

Barros de Oliveira, C., Torres de Medeiros, I. R., Frota, N. A. F., Greters, M. E., \& Conforta, A. B. (2008). Balance control in hemiparetic stroke patients: Main tools for evaluation, Jurnal of Rehabilitation Research \& Development (JRRD), 45 (8) :1215 - 1226

Benaim, C., Perennou, D.A., Villy, J., Rousseaux, M., \& Pelissier, J.Y. (1999). Validation of a standardized assessment of postural control in stroke patients : the postural assessment scale for stroke patients (PASS). Journal of The American Heart Association : Stroke. 30 : 1862-1868.
Gemari. (2008). Krisis global sebabkan stres : stroke di Indonesia tambah besar (edisi 94).

Gjelsvik, B. E. B. (2008). The bobath concepts in adult neurology. New York: Thieme.

Misbach, J. \& Ali, W. (2001). Stroke in Indonesia: a first large prospective hospital-based study of acute stroke in 28 hospitals in Indonesia. J. Cli. Neuros., 8(3): 245-249

Raine, S., Meadows, L., LynchEllerington, M. (2009). Bobath concept: theory and clinical practice in neurological rehabilitation. United Kingdom : Wiley-Blackwell.

Rode, G., Tiliket, C., \& Boisson, D. (1997). Predominance of postural imbalance in left hemiparetic patients. Scand J Rehabil Med. 29(1):11-16

Schaechter, J.D. (2004). Motor rehabilitation and brain plasticity after hemiparetic stroke. J.Pneurobio. 73: 61-72.

Shumway-Cook, A. \& Woollacott, MH. (2001). Motor control: Theory and practical applications. 2nd ed. Philadelphia (PA): Lippincott, Williams \& Wilkins

Verheyden, G., Nieuwboer, A., van de Winckel, A., \& de Weerdt, W. (2007). Clinical tools to measuremen trunk performance after stroke : a systematic review of the literature. Clinical Rehabilitation. 21 : 387-394. 